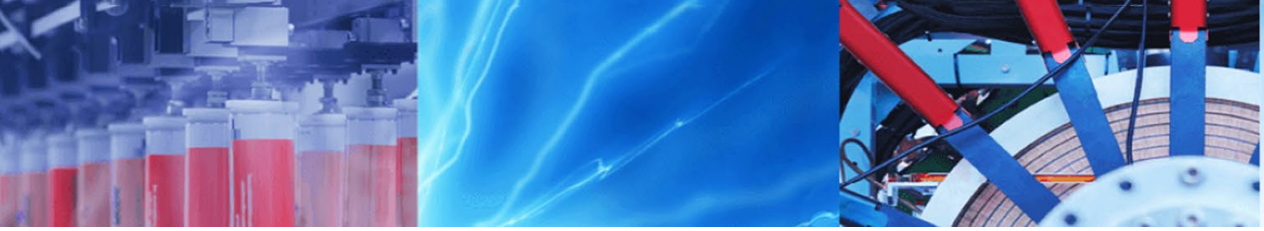

Research Article

\title{
Mechanical, moisture absorption, biodegradation and physical properties of nanoclay-reinforced wood/plant oil composites
}

\author{
Moon Mandal ${ }^{1} \cdot$ Zakaria Halim $^{1} \cdot$ Tarun K. Maji $^{1}$
}

Received: 25 June 2019 / Accepted: 6 January 2020 / Published online: 21 January 2020

(c) Springer Nature Switzerland AG 2020

\begin{abstract}
Composite materials were prepared via a compression molding process utilizing modified soybean oil, wood flour, and rosin derivative. Montmorillonite (MMT) was used as a nano-filler to increase the properties of composites prepared from methacrylic anhydride based epoxidized soybean oil co-polymerized with divinyl acrylicpimaric acid. The synthesized composites were characterized by Fourier transform infrared spectroscopy and X-ray diffractometry. The MMT filled composites showed enhanced mechanical properties compared to MMT free composites. The thermal stability of MMT filled composites was higher compared to those of unfilled composites due to the development of a protective residue. The morphological study by scanning electron microscope showed that the nano-clay particles were well dispersed throughout the matrix. The effects of MMT on biodegradability of the wood composites was analyzed by UV-spectrophotometry. In addition to that, the mechanical properties of the composite were evaluated after exposure to microorganism attack.
\end{abstract}

Keywords Wood composites · Rosin derivatives · Thermal properties · Bio-degradation · Mechanical properties

\section{Introduction}

In the past few decades, current environmental guidelines and societal distress have provoked the necessity to develop bio-based materials and other innovative processes that can emancipate worldwide dependency on fossil fuels. These bio-based materials are used as replacement for various traditional materials (i.e. metals), due to their intrinsic properties such as ease of construction, structural control, productivity, abundance, less laborious process, and low cost [1]. Composites made from synthetic reinforcements and polymer matrices are losing popularity owing to their serious environmental issues and high cost [2]. Bio-based composites are witnessing numerous applications due to their enhanced properties and the various advantages they have over petroleum based resources in terms of renewability, availability, and biodegradability [3]. One crucial effort has been the preparation and utilization of bio-based materials from environmentally favorable starting materials, such as starch, cellulose, straw, wood fibers, plant oils, proteins etc.

Wood is an important natural resource that addresses various survival and developmental needs of human society. However, solid wood has some disadvantages like dimensional instability which restrict its application in diverse sectors. The reason for such defects is due to the abundance of hydroxyl groups in the wood cell walls, which swell the fibres in the presence of moisture or water. As a consequence, the physical, mechanical, and chemical features of wood are negatively influenced [4]. Hence, the properties of wood can be enriched by the fabrication of wood polymer composites (WPCs) [5]. WPCs are known to have greater longevity and lower maintenance cost, desirable dimensional stability, better screening to moisture and biological degradation, low price compared to composites prepared with other fibers, and preferable recyclability [6]. Conventional chemical processing has turned out to be productive in enhancing composite's mechanical

Tarun K. Maji, tkm@tezu.ernet.in | 'Department of Chemical Sciences, Tezpur University, Tezpur, Assam 784028, India. 
properties, dimensional stability, and stiffness. Apart from that, fire retardation, UV screening, and biological resistance can be considerably enhanced by the incorporation of nanomaterials within the wood composites [7]. Wood polymer nanocomposites (WPNCs) are materials in which nano-sized inorganic particles having at least one dimension in the nanometer range are dispersed in an organic polymeric matrix [8]. WPNCs have superior properties compared to the conventional composites due to their nano level characteristic which maximizes the interfacial adhesion [9]. Its improved barrier properties, chemical hindrance, and the exterior finish make it a worthy material for various applications such as automotive, constructions, marines, consumer products, packaging, electronic, and aerospace industries, etc. [10, 11].

Vegetable oils such as soybean and linseed oil are found to be suitable for the synthesis of resins to substitute the conventional petrochemical based polymers $[12,13]$. Vegetable oil has the advantage of being one of the most affordable and eco-rich products available in large quantities. Soybean oil is an unsaturated triglyceride, which mainly consists of linolenic acid, linoleic acid, oleic acid, palmitic acid, and stearic acid. Triglycerides are composed of three fatty acid chains joined by a glycerol center. Soybean oil contains active functional groups such as double bonds which can be altered chemically to fabricate polymers having desirable properties $[14,15]$. The motive for functionalization is to increase the molecular weight and the crosslinking density in order to provide stiffness in the polymeric chains, which leads to elevated mechanical properties [16]. The triglyceride molecules in soybean oil are modified through epoxidation reaction that results in the formation of epoxidized soybean oil (ESO). Epoxidized soybean oil is not reactive enough. One of the ways to make it reactive is to introduce the double bond which can be further utilized for polymerization reaction [17]. Thus ESO is modified further with methacrylic acid and methacrylic anhydride to produce methacrylic anhydride modified epoxidized soybean oil (MAESO). Reactive diluent like styrene (St) or divinylbenzene (DVB) having low molecular weight, which can be utilized as co-monomers to make the thermo-physical and mechanical properties of plant oil based resins acceptable for structural applications. However, both St and DVB are volatile organic compounds, and hence, efforts have been made to substitute all or part of St or DVB with environmentally favorable comonomers $[18,19]$.

Rosin is a solid form of resin obtained from pines containing isomeric abietic acids (40-60\%) and pimaric acids (9-27\%). Rosin is abundant in nature, low cost, and biodegradable it can be functionalized further to convert it into a promising renewable feedstock in polymer synthesis. Rosin acids are similar to cycloaliphatic or aromatic compounds in terms of molecular rigidity, owing to their huge hydrogenated phenanthrene ring composition. These derivatives are reported to be used as a replacement to various petroleum-derived rigid monomers in the synthesis of polymers [20,21]. Rosin derivatives can be co-polymerized with soybean oil based polymers to develop thermosetting resins that are entirely bio-based [22].

Nano-fillers at a lower level are used to minimize the processing difficulties and also to increase the mechanical, chemical and thermal properties. The incorporation of nanomaterials such as $\mathrm{TiO}_{2}, \mathrm{SiO}_{2}$, nano-clay, CNTs, $\mathrm{ZnO}$, etc. to the polymeric matrix shows an improvement in the properties of WPCs. Nanoclays are fine-grained particles regarded as hydrous silicates with a sheet-like structure stacked above one another. Nanoclay reinforced polymer composites have received immense attention in the area of nano-composites due to their exceptional capability of enhancing the mechanical, thermal and barrier properties even at a low level of addition [23, 24]. The enhanced performance of the nanocomposites could only be perceived at nanoscale diffusion and are achieved by the exfoliation of nanofiller $[25,26]$. The petroleum-derived polymers are incompatible with clay minerals due to the dissimilarity in their surface energies, and hence the exfoliation of clay platelets is one of the major challenges experienced during the preparation of nanocomposites. This can be overcome by surface modification where surfactants having compatibility with the organic polymers are exchanged with exchangeable cations present in the nanoclay which increases the spacing between the layers (d-spacing) [27].

In our earlier work, wood composites were developed by using a derivative of rosin acid, i.e. divinyl acrylicpimaric acid (DAPA) containing two reactive divinyl functionalities and MAESO resin to form a strong network structure [28]. The improvement in various properties of the composite was also reported due to the presence of hydrophenanthrene moiety of rosin derivative. The current work aims to study the properties of wood polymer composites prepared by using wood, MAESO resin, DAPA, and MMT. A tiny part of the probable cross-linked structure of WPC is shown in Scheme 1. The properties of composites with different percentages of nano-clay were investigated and reported. Furthermore, surface morphology, mechanical properties, thermal stability, flame retardancy, biodegradability, dimensional stability and chemical resistance of the WPCs were investigated both with and without nano-clay. 


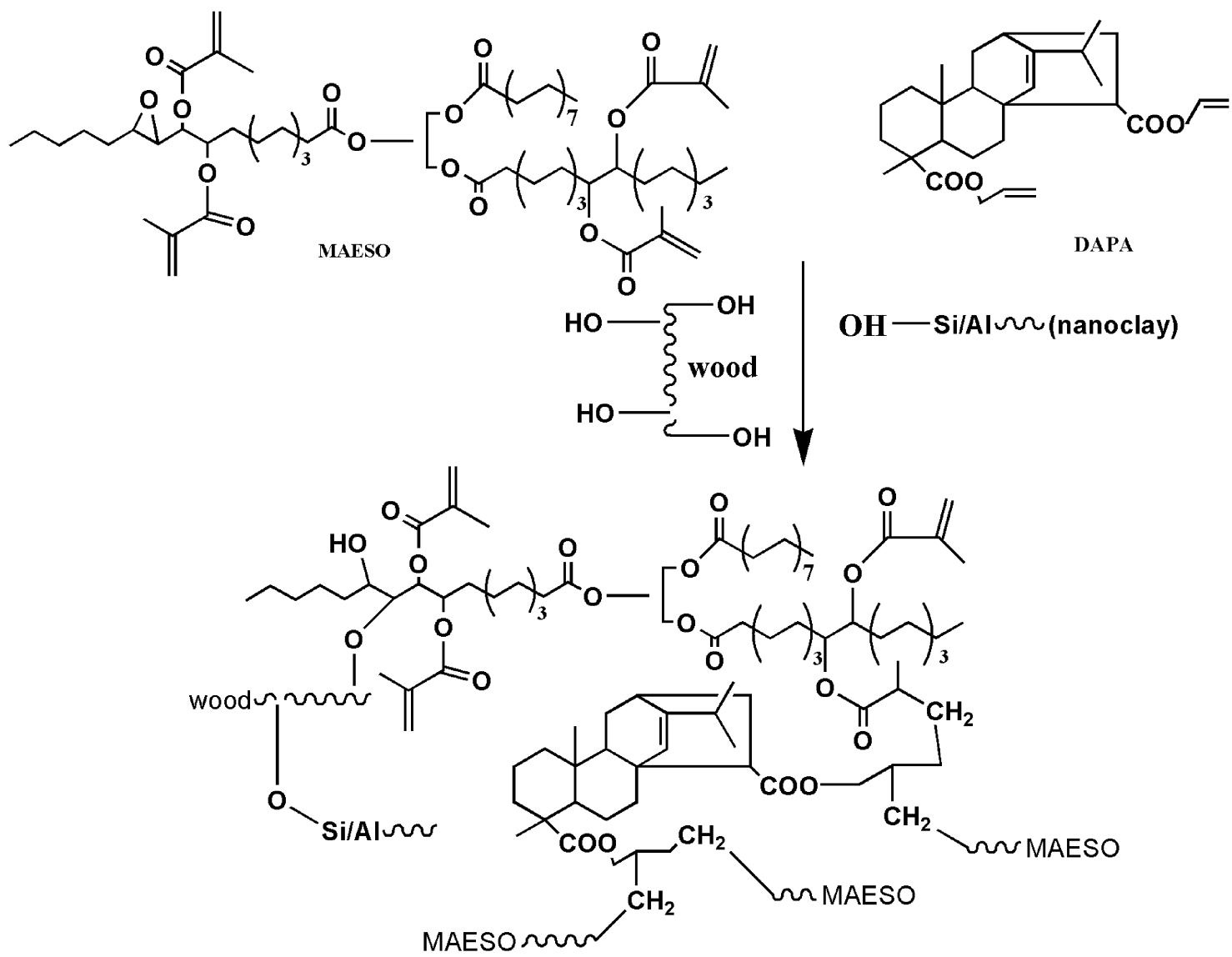

MAESO/DAPA/WF/NC

Scheme 1 A plausible cross-linked structure of wood polymer composite reinforced with nanoclay

\section{Experimental procedure}

\subsection{Raw materials}

Epoxidized soybean oil (ESO) was bought from Agarwal organics, Indore (India). The physicochemical properties of ESO were reported in our previous paper [29]. Nanoclay (montmorillonite clay surface modified with 15-35 wt\% octadecylamine and $0.5-5$ wt $\%$ aminopropyltriethoxysilane), Methacrylic anhydride, Cobalt(II)2ethylhexanoate were purchased from Sigma Aldrich, USA. Methacrylic acid, Methyl ethyl ketone peroxide (MEKP), $\mathrm{N}$-methylimidazole and Diethyl ether were purchased from Merck India Limited, Mumbai (India). Sodium Hydroxide and Acrylic acid were procured from Sisco Research Laboratories Pvt. Ltd, India. Hydroquinone was purchased from G.S. Chemical testing laboratory and allied industries (India). Rosin acid was bought from Alfa Aesar, USA. Petroleum ether was obtained from
Ranbaxy Chemicals, India. Allyl Bromide was obtained from Loba Chemie, Mumbai, India. All other solvents were used as received.

Softwood, Krishnachura (Delonix regia) was gathered from the local forest of Tezpur, Assam (India). The collected wood specimens were chopped into small pieces $(\approx 2-3 \mathrm{~cm})$, washed with water and soap solution. It was treated with $1 \% \mathrm{NaOH}$ solution to enhance the surface roughness and remove the lignin. It was then dried in an oven, grounded and sieved using 70 mesh sized sieve to obtain the wood powder [29].

\subsection{Synthesis of acrylicpimaric acid (APA)}

The synthesis of APA was carried out according to the procedure reported in the literature [28]. 


\subsection{Synthesis of divinyl acrylicpimaric acid (DAPA)}

To synthesize divinyl acrylicpimaric acid (DAPA), $5 \mathrm{~g}$ of APA, $3.5 \mathrm{~g}$ of potassium carbonate with $4.33 \mathrm{~mL}$ of acetone were placed in a round-bottom flask. $7 \mathrm{~g}$ of allyl bromide $(0.6 \mathrm{~mol})$ solution with $2 \mathrm{~mL}$ of acetone was added to the flask drop wise at $50^{\circ} \mathrm{C}$. The mixture was refluxed for $12 \mathrm{~h}$ at $70^{\circ} \mathrm{C}$ after which it was cooled to room temperature and then cleansed with dichloromethane (DCM). The collection of the organic phase was done by an extraction process and again cleansed several times with distilled water and then the solvent was separated in a rotary evaporator. Finally, a yellow colored product was obtained, weighing $4.2 \mathrm{~g}$ with a yield of $81 \%$. The characterization of the structure was done by FTIR and ${ }^{1} \mathrm{H}-\mathrm{NMR}$ spectroscopy [28].

\subsection{Synthesis of methacrylic anhydride epoxidized soybean oil (MAESO)}

The preparation of MAESO was described in our previous paper [29]. Briefly, MAESO was prepared by the reaction of epoxidized soybean oil (ESO) with methacrylic acid to form methacrylated epoxidized soybean oil (MESO), which was further functionalized with methacrylic anhydride to form methacrylic anhydride modified epoxidized soybean oil (MAESO).

\subsection{Development of wood polymer composite sheets reinforced with nanoclay}

In a 3-necked round bottom flask, DAPA and nanoclay were added to MAESO resins with the predetermined ratio as shown in Table 1. After extensive stirring, cobalt (II) 2-ethylhexanoate solution (promoter) and methyl ethyl ketone peroxide (catalyst) were added with vigorous stirring to get a homogeneous mixture. To this mixture wood powder was added and again stirred intensely with a mechanical stirrer. Finally, the whole mixture was poured in a tray, dried and then composite sheets were prepared. The nano-clay reinforced composite sheets were prepared with the help of a compression molding press (S.C. Dey Co. Kolkata). The temperature, pressure, and time for molding were kept at $140{ }^{\circ} \mathrm{C}, 50 \mathrm{MPa}$, and 30 min respectively.

\subsection{Bacterial media}

Mineral salt medium having the following composition was prepared for bacterial growth: $4.75 \mathrm{~g}$ of $\mathrm{KH}_{2} \mathrm{PO}_{4}, 2.0 \mathrm{~g}$ of $\mathrm{Na}_{2} \mathrm{HPO}_{4}, 2.0 \mathrm{~g}$ of $\left(\mathrm{NH}_{4}\right)_{2} \mathrm{SO}_{4}, 1.2 \mathrm{~g}$ of $\mathrm{MgSO}_{4} \cdot 7 \mathrm{H}_{2} \mathrm{O}$, $100 \mathrm{mg}$ of $\mathrm{MnSO}_{4} \cdot 5 \mathrm{H}_{2} \mathrm{O}, 100 \mathrm{mg}$ of $\mathrm{CuSO}_{4} \cdot 7 \mathrm{H}_{2} \mathrm{O}, 70 \mathrm{mg}$ of $\mathrm{ZnSO}_{4} \cdot 7 \mathrm{H}_{2} \mathrm{O}, 10 \mathrm{mg}$ of $\mathrm{H}_{3} \mathrm{BO}_{3} \cdot 5 \mathrm{H}_{2} \mathrm{O}, 10 \mathrm{mg}$ of $\mathrm{MoO}_{3}, 1 \mathrm{mg}$ of $\mathrm{FeSO}_{4} \cdot 7 \mathrm{H}_{2} \mathrm{O}$, and $0.5 \mathrm{mg}$ of $\mathrm{CaCl}_{2} \cdot 2 \mathrm{H}_{2} \mathrm{O}$ were dissolved in $1000 \mathrm{~mL}$ of distilled water. $100 \mathrm{~mL}$ of this liquid culture medium was then poured into a $250 \mathrm{~mL}$ conical flask and sterilized in an autoclave at $121^{\circ} \mathrm{C}, 15 \mathrm{lb}$ per inches' square pressure for $15 \mathrm{~min}$. The autoclaved media was then allowed to cool to room temperature, and composite samples were added into the media under sterile condition inside a laminar air flow hood. Media containing only polymer samples without bacteria was also cultured as the control.

\subsection{Bacterial strain}

Pseudomonas aeruginosa MTCC 2297 was grown on nutrient broth at $37^{\circ} \mathrm{C}$ for $18 \mathrm{~h} .1 \mathrm{~mL}$ of bacterial culture was centrifuged at $6000 \mathrm{rpm}$ for $20 \mathrm{~min}$ at room temperature, and the pellets were washed with $0.9 \% \mathrm{NaCl}$ and re-suspended in $1 \mathrm{~mL}$ of mineral salt medium. Thereafter, $0.5 \mathrm{~mL}$ of the culture medium $(0.40 . D 660 \mathrm{~nm}$ ) was inoculated in $50 \mathrm{~mL}$ centrifuge tube containing $10 \mathrm{~mL}$ of media for each test. The test tubes were then incubated at $37^{\circ} \mathrm{C}, 120 \mathrm{rpm}$ for the degradation study. The absorbance at $660 \mathrm{~nm}$ was recorded every month.

\section{Characterization}

\subsection{Fourier transform infrared (FTIR) spectroscopy}

FTIR study was performed in transmission mode over the wavenumber range of $4000-500 \mathrm{~cm}^{-1}$ by a Nicolet
Table 1 Formulations of various wood polymer composites

\begin{tabular}{lllllll}
\hline Sample code & \multicolumn{2}{l}{ Ingredients } & \multicolumn{2}{l}{} \\
\cline { 2 - 7 } & MAESO (resin) & DAPA (wt\%) & $\begin{array}{l}\text { Pro- } \\
\text { moter } \\
\text { (wt\%) }\end{array}$ & MEKP (wt\%) & $\begin{array}{l}\text { Wood } \\
\text { flour } \\
\text { (WF) }\end{array}$ & $\begin{array}{l}\text { Nanoclay } \\
\text { (NC) (wt\%) }\end{array}$ \\
\hline MAESO/DAPA/WF/NC0 & 42 & 16.5 & 0.5 & 1 & 40 & 0 \\
MAESO/DAPA/WF/NC1 & 42 & 16.5 & 0.5 & 1 & 39 & 1 \\
MAESO/DAPA/WF/NC3 & 42 & 16.5 & 0.5 & 1 & 37 & 3 \\
MAESO/DAPA/WF/NC5 & 42 & 16.5 & 0.5 & 1 & 35 & 5 \\
\hline
\end{tabular}

MAESO, methacrylic anhydride epxidized soybean oil; DAPA, divinyl acrylicpimaric acid; WF, wood flour; NC, nano-clay 
(Madison, WI) FTIR impact 410 spectrophotometer using $\mathrm{KBr}$ pellets. The samples were prepared by keeping the ratio of thoroughly grounded composite sample to $\mathrm{KBr}$ as 1:20 approximately. Both the powder sample and $\mathrm{KBr}$ were homogenously grounded in a mortar. Around $5 \mathrm{mg}$ of the sample mixture was taken and pressed in hydraulic press in order to make the pellets.

\subsection{Powder X-ray diffraction (XRD) study}

The powder X-ray diffraction measurements were performed at room temperature on a D8 FOCUS X-ray diffractometer (Bruker Axs, Germany) using Cu Ka $(\lambda=0.154 \mathrm{~nm}$ ) radiation over the range of $2 \theta=3^{\circ}-50^{\circ}$ at a scanning rate of $1 \% \mathrm{~min}$.

\subsection{Transmission electron microscopy (TEM)}

The distribution of nano-clay in the composite samples was studied by using a transmission electron microscope (JEM-2100, Japan) at an accelerating voltage of 60-200 kV. The samples were embedded with epoxy resin for the preparation of ultra-thin as well as polished sections. An ultramictrotome fitted with a diamond knife was used for ultrathin sectioning of the surfaces. The sections were then stained with $1 \mathrm{wt} \%$ of uranyl acetate for sufficient contrast, mounted on grids and examined.

\subsection{Mechanical properties}

The tensile and flexural tests for both with and without nano-clay reinforced composites were analyzed by Universal Testing Machine (Zwick, model Z010, Germany) according to ASTM D-638 and D-790 respectively. For this test, three specimens of each category were analyzed to calculate the average value of their tensile and flexural strength. The dimensions of the samples taken were $(10 \mathrm{~cm} \times 0.5 \mathrm{~cm} \times 2 \mathrm{~cm})$ and $(1 \mathrm{~cm} \times 1 \mathrm{~cm} \times 10 \mathrm{~cm})$.

\subsection{Statistical analysis}

Data were expressed as mean \pm standard deviation (SD). The mechanical property results were analyzed statistically using one-way analysis of variance (ANOVA).

\subsection{Hardness test}

The hardness of the samples was measured with a durometer (model RR12) according to ASTM D-2240. It was expressed as shore D. For this test, three specimens of each category was analyzed.

\subsection{Thermogravimetric analysis (TGA)}

It was performed on a thermogravimetric analyzer (TGA50 , Shimadzu, Japan) by using high purity nitrogen as the purge gas at a scanning rate of $5^{\circ} \mathrm{C} \mathrm{min}{ }^{-1}$ from 25 to $600{ }^{\circ} \mathrm{C}$. The nitrogen flow rate was maintained at

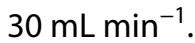

\subsection{Limiting Oxygen Index (LOI) Test}

LOI values were measured on a flammability tester (S.C. Dey Co., Kolkata) according to the ASTM D-2863 method. The sample was placed vertically in the sample holder of the LOI apparatus. The ratio of nitrogen and oxygen at which the samples continued to burn for at least $30 \mathrm{~s}$ was recorded and examined further.

Limiting Oxygen Index

$$
=\text { Volume of } \mathrm{O}_{2} /\left(\text { Volume of } \mathrm{O}_{2}+\text { Volume of } \mathrm{N}_{2}\right)
$$

\subsection{Scanning electron microscope (SEM) study}

Scanning electron microscopy was performed on a scanning electron microscope, (JEOL JSM-6390LV, Japan) at an accelerating voltage of 5-10 kV. The fractured surface of the composite sample was mounted on a sample holder and sputter-coated with platinum.

\subsection{Water vapor uptake and dimensional stability test}

All the test specimens were oven dried and conditioned at room temperature $\left(30^{\circ} \mathrm{C}\right)$ with $30 \%$ relative humidity before the test. Three samples of each category were cut into pieces of $(2.5 \mathrm{~cm} \times 0.5 \mathrm{~cm} \times 2.5 \mathrm{~cm})$, and weights of the oven-dried samples were measured. The test was carried out by placing the samples at $65 \%$ relative humidity maintaining a temperature of $30^{\circ} \mathrm{C}$. The excess water was removed and weights of the specimens were recorded after $6,12,24,36,48,60,72,84,96,120 \mathrm{~h}$. The water uptake or water adsorption (wt\%) was then calculated based on the ratio of the weight difference between the conditioned and dried samples to the dried sample weight. Similarly, volumetric swelling was measured as a change in volume and is expressed as the percentage of volume increase compared to oven-dried samples.

Water vapor uptake $(\%)=\left(W_{t}-W_{o}\right) / W_{0} \times 100$ 
where " $W_{t}$ " is the weight of the specimen after moisture absorption and " $W_{\mathrm{o}}$ " is the weight of oven dried specimen.

Volumetric swelling was considered as a change in volume and is expressed as the percentage of volume increase compared to oven-dried samples.

$\%$ Volumetric swelling $=\left(\mathrm{V}_{\mathrm{f}}-\mathrm{V}_{\mathrm{o}}\right) / \mathrm{V}_{\mathrm{o}} \times 100$

where " $V_{f}$ " is the volume of the specimen after water absorption and " $V_{0}$ " is the volume of the oven-dried specimen.

\subsection{Chemical resistance test}

All the specimens were cut into pieces of $(2.5 \mathrm{~cm} \times 0.5 \mathrm{~cm} \times 2.5 \mathrm{~cm})$ and were kept immersed in $4 \%$ $\mathrm{NaOH}$ solution and $4 \%$ acetic acid solution for $24 \mathrm{~h}$ and 7 days. The volumes of these samples were measured using Vernier callipers. The percentage of swelling was calculated by using the equation as given below,

$\%$ Swelling $=\left(\mathrm{V}_{\mathrm{c}}-\mathrm{V}_{\mathrm{o}}\right) / \mathrm{V}_{\mathrm{o}} \times 100$

where ' $V_{c}$ ' is the volume of the wood polymer composite after immersion in chemicals and ' $V_{o}$ ' is the volume of the composite before immersion in chemicals.

\subsection{Biodegradation study}

The composite samples treated with various percentage of MMT were exposed to cellulolytic bacterial strain in liquid broth culture medium for the biodegradation study. Two samples of each category were analyzed for the biodegradation study. The bacterial growth and biodegradation rate in the broth culture medium were studied using a UV visible spectrophotometer (Shimadzu Corporation UV2450 spectrophotometer, Kyoto, Japan) at $600 \mathrm{~nm}$ against blank culture media under sterile condition. The bacterial growth on the samples was plotted with respect to time.

\section{Results and discussion}

\subsection{FTIR spectroscopy}

FTIR spectra of nanoclay, wood flour, and composites loaded with different MMT percentages are shown in Fig. 1. The FTIR spectrum of nanoclay (curve a) showed a peak at $3424 \mathrm{~cm}^{-1}$ corresponding to $-\mathrm{OH}$ stretching, $2930 \mathrm{~cm}^{-1}$ and $2850 \mathrm{~cm}^{-1}$ which were due to asymmetric and symmetric vibration of methylene group $\left(\mathrm{CH}_{2}\right)$ in the organic compound, $1628 \mathrm{~cm}^{-1}$ due to $-\mathrm{OH}$ bending and

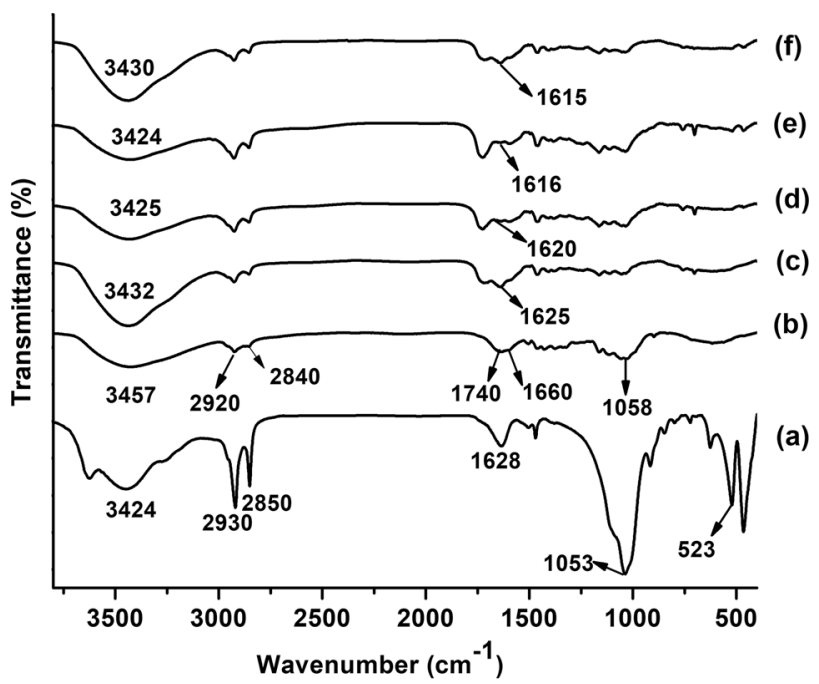

Fig. 1 The FTIR spectra of (a) nanoclay, (b) wood four, (c) MAESO/ DAPA/WF/NCO, (d) MAESO/DAPA/WF/NC1, (e) MAESO/DAPA/WF/ $\mathrm{NC} 3$ and (f) MAESO/DAPA/WF/NC5

$1053-460 \mathrm{~cm}^{-1}$ for oxide bonds of metals like $\mathrm{Si}, \mathrm{Al}, \mathrm{Mg}$, etc. Wood flour (curve b) shows the presence of bands at $3457 \mathrm{~cm}^{-1}$ for $-\mathrm{OH}$ stretching, 2920 and $2840 \mathrm{~cm}^{-1}$ due to $-\mathrm{CH}_{2}$ asymmetric stretching in alkyl groups for cellulose and lignin, $1740 \mathrm{~cm}^{-1}$ due to $\mathrm{C}=\mathrm{O}$ stretching of hemicellulose, $1660 \mathrm{~cm}^{-1}$ due to $-\mathrm{OH}$ bending, and $1058 \mathrm{~cm}^{-1}$ and $1000-650 \mathrm{~cm}^{-1}$ due to $-\mathrm{CO}$ stretching and out of the plane $-\mathrm{CH}$ bending vibration respectively.

Figure 1, curve (c-f) shows the spectra of composites loaded with different percentage of nano-clay. In MAESO/DAPA/WF/NCO (curve c), the hydroxyl peak that appeared at $3457 \mathrm{~cm}^{-1}$ for virgin wood was found to shift to $3432 \mathrm{~cm}^{-1}$. Similarly, for MAESO/DAPA/WF/NC1 (curve d), MAESO/DAPA/WF/NC3 (curve e) and MAESO/DAPA/ WF/NC5 (curve f), the hydroxyl peaks were found to shift to $3425 \mathrm{~cm}^{-1}, 3424 \mathrm{~cm}^{-1}$ and $3430 \mathrm{~cm}^{-1}$ respectively. The shifting of hydroxyl peak to lower wavenumber might be attributed to the crosslinking reaction caused by the participation of $-\mathrm{OH}$ group of clay and wood. However, at higher clay (5\%) loading, the shifting of hydroxyl peak to lower wave number was almost similar to that of clay free composites. This might be due to decrease in interaction among the components caused by the agglomeration of nanoclay. Hazarika et al. reported the shifting of hydroxyl peak to lower wavenumber while studying the FTIR analysis of softwood polymer nanocomposites reinforced with $\mathrm{ZnO}$ nanoparticles and nanoclay [30]. In the composites containing $5 \mathrm{wt} \%$ nanoclay, the hydroxyl peak shifted to higher wave number (i.e. $3430 \mathrm{~cm}^{-1}$ ) compared to composites having $3 \mathrm{wt} \%$ nanoclay. This might be due to the decrease in the interaction of MMT particles with the composite matrix. Again, the $-\mathrm{OH}$ 
bending peak that appeared at $1628 \mathrm{~cm}^{-1}$ for MMT was found to shift to $1625 \mathrm{~cm}^{-1}$ for MAESO/DAPA/WF/NCO (curve c), $1620 \mathrm{~cm}^{-1}$ for MAESO/DAPA/WF/NC1 (curve d), $1616 \mathrm{~cm}^{-1}$ for MAESO/DAPA/WF/NC3 (curve e) and $1615 \mathrm{~cm}^{-1}$ for MAESO/DAPA/WF/NC5 (curve f), respectively. This might be due to the participation of hydroxyl group of clay with wood, nanoclay, co-monomer DAPA and MAESO resin $[29,31]$.

\subsection{X-ray diffraction studies}

The XRD patterns for wood flour and MMT are shown in Fig. $2 \mathrm{~A}$ and for composites reinforced with different percentages of MMT are illustrated in Fig. 2B. In Fig. 2A, the peak (curve a) that appeared at $2 \theta=22.90^{\circ}$ was due to the diffraction of (002) plane of wood cellulose. The XRD pattern for nanoclay in Fig. $2 \mathrm{~A}$ (curve b), showed peaks at around $2 \theta=4.03^{\circ}$ and $27.20^{\circ}$. The intensity of peak due to wood cellulose decreased in all the composites with the inclusion of MMT inside the polymer matrix. The position of band appeared at $2 \theta=22.50^{\circ}$ in nanoclay free composites was found to shift to $21.42^{\circ}$ for MAESO/DAPA/WF/NC1 (curve b), $20.68^{\circ}$ for MAESO/DAPA/WF/NC3 (curve c) and $20.74^{\circ}$ for MAESO/DAPA/WF/NC5 (curve d) from $22.90^{\circ}$ as shown in Fig. $2 \mathrm{~A}$ (curve a). The decrease in peak intensity and shifting of broad peak indicated that the crystallinity in the wood decreased and some nano-clay laminae were incorporated into the amorphous area of wood cellulose. Comparing the diffraction patterns of the clay-reinforced composite samples, the peak for nanoclay at $2 \theta=4.03^{\circ}$ was found to shift towards lower angle $\left(3.90^{\circ}-3.98^{\circ}\right)$, indicating occurrence of significant intercalation of polymer chains between the galleries of the clay [8].

\subsection{Transmission electron microscopy (TEM)}

The distribution of the nano-clay into the polymer matrix was inspected by a transmission electron microscope that is shown in Fig. 3. The silicate layers were visible as dark grey lines in the TEM images of $3 \mathrm{wt} \%$ nano-clay containing composite (i.e. MAESO/DAPA/WF/NC3). This suggested that the clay layers were delaminated and distributed into the polymer matrix of the composites. However, the clay particles were found to agglomerate in $5 \mathrm{wt} \%$ nano-clay containing composite (i.e. MAESO/ DAPA/WF/NC5). Therefore, it could be said that the clay layers were not sufficiently delaminated and either very less polymers would intrude into the gallery spacing. It could be concluded that the dispersion of clay particles in $3 \mathrm{wt} \%$ MMT loading composite was better than that of $5 \mathrm{wt} \%$ MMT containing composites [32].

\subsection{Scanning electron microscope (SEM)}

The SEM micrographs of composites loaded with various percentage of clay are shown in Fig. 4. The rough surface observed for MAESO/DAPA/WF/NCO (Fig. 4a) and MAESO/DAPA/WF/NC1 (Fig. 4b) composites indicated a poor interaction among wood, MAESO resin, and DAPA. With the increase in clay content, the surface roughness decreased up to a certain extent. For MAESO/DAPA/
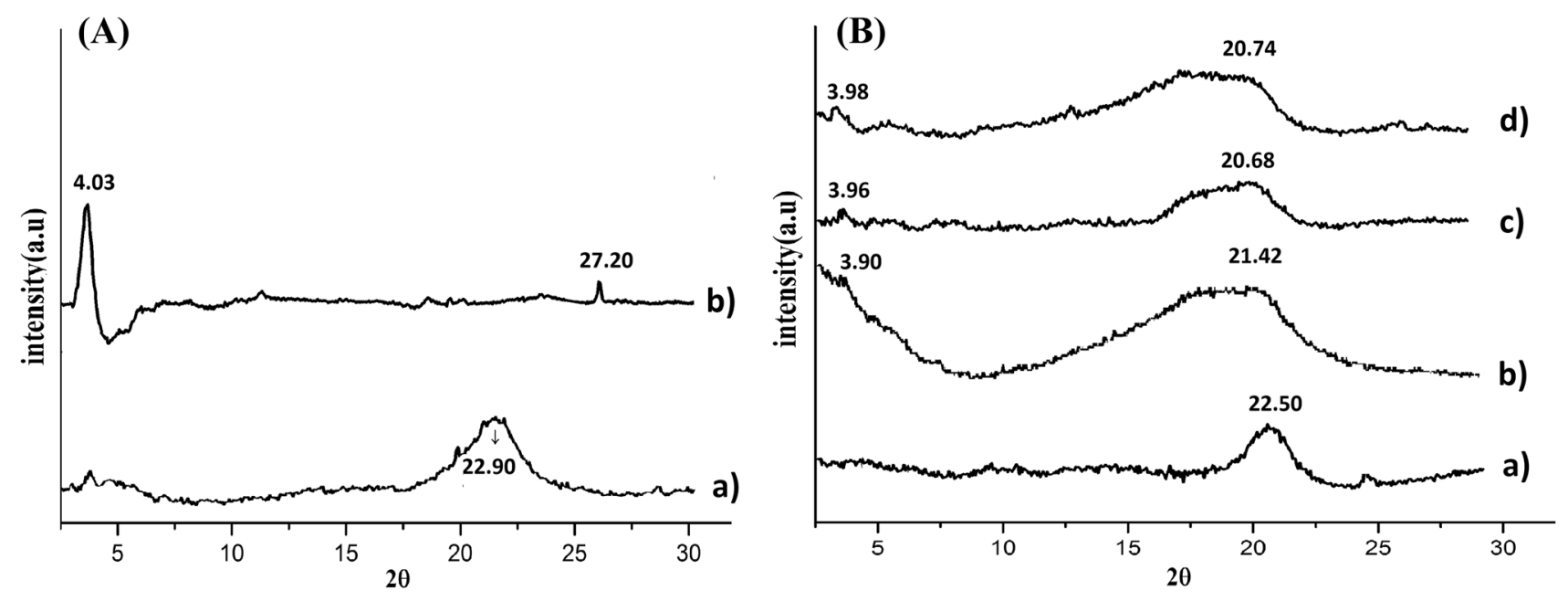

Fig. 2 XRD patterns for A-(a) wood flour, (b) MMT, (B)—(a) MAESO/DAPA/WF/NC0, (b) MAESO/DAPA/WF/NC1, (c) MAESO/DAPA/WF/NC3 and (d) MAESO/DAPA/WF/NC5 

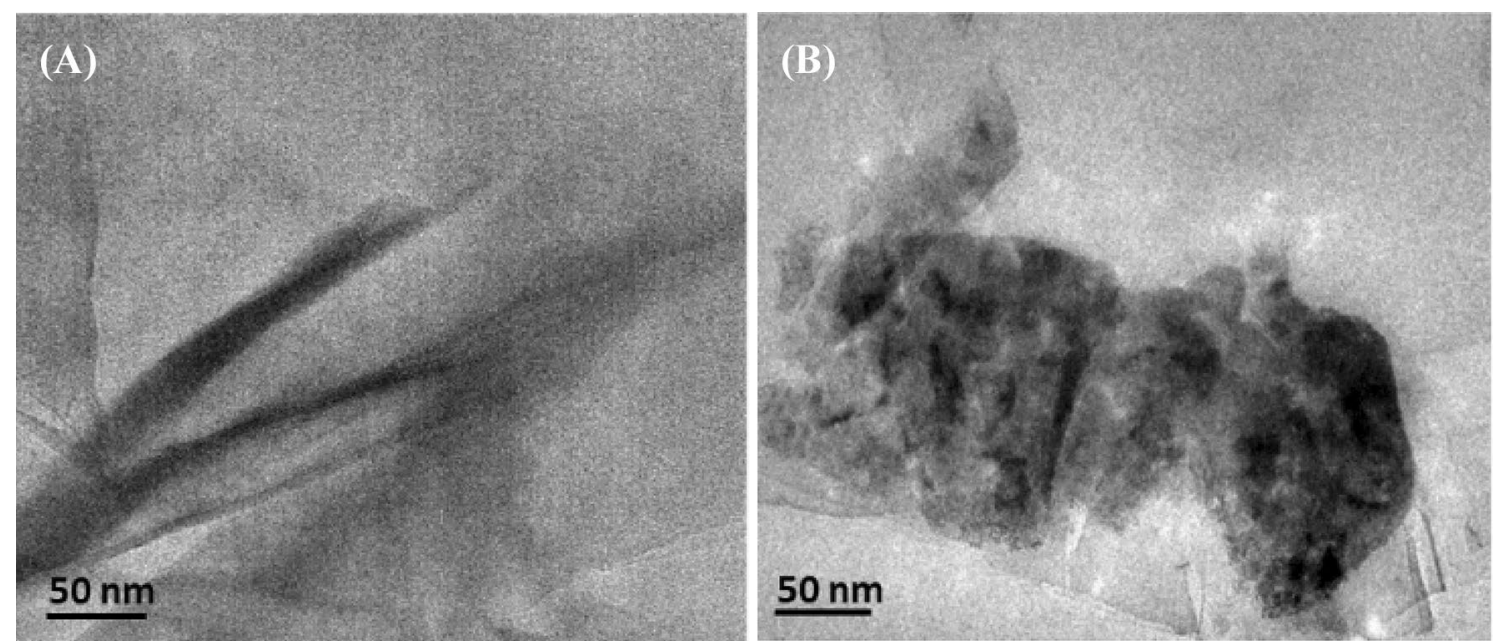

Fig. 3 TEM images of a MAESO/DAPA/WF/NC3 and $\mathbf{b}$ MAESO/DAPA/WF/NC5
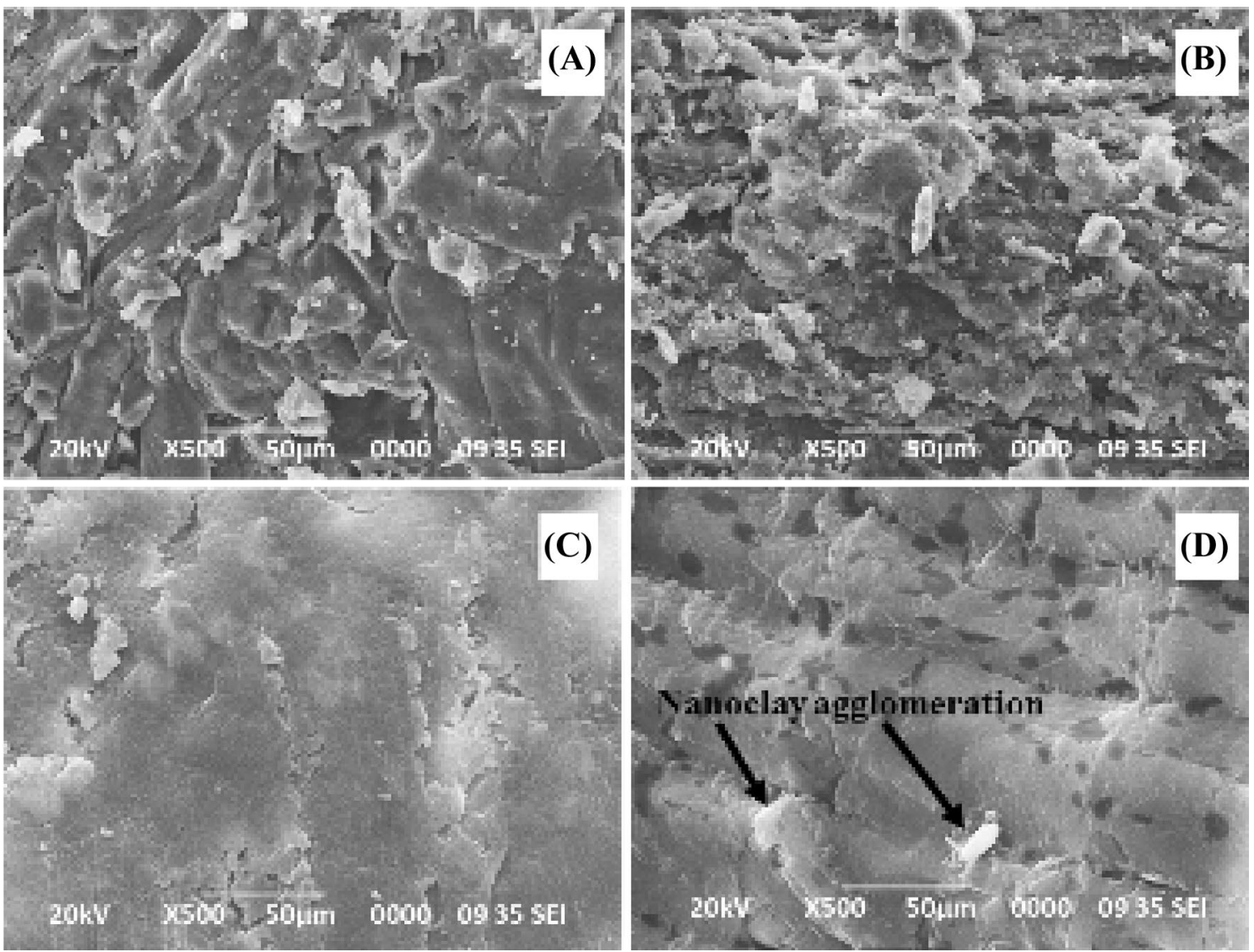

Fig. 4 SEM images of a MAESO/DAPA/WF/NCO, b MAESO/DAPA/WF/NC1, c MAESO/DAPA/WF/NC3 and d MAESO/DAPA/WF/NC5

WF/NC3 (Fig. 4c) composite, the clay particles were dispersed properly into the polymer matrix due to which a smooth surface was observed. This indicated a better interaction between MAESO, wood flour, and rosin derivative. However, when the clay content was increased to
$5 \mathrm{wt} \%$, the surface roughness increased, which might be due to less compatibility between various components of wood composites. In MAESO/DAPA/WF/NC5 (Fig. 4d), the clay particles might have agglomerated due to which

\section{SN Applied Sciences}


Table 2 Flexural, tensile, hardness and LOI values of the WPCs both with and without nano-clay

\begin{tabular}{lclll}
\hline Sample & Flexural strength $(\mathrm{MPa})$ & Tensile strength $(\mathrm{MPa})$ & Hardness shore D & LOI $(\%)$ \\
\hline MAESO/DAPA/WF/NC0 & $65.05( \pm 0.38)$ & $31.62( \pm 0.68)$ & $70.46( \pm 0.97)$ & 55 \\
MAESO/DAPA/WF/NC1 & $67.13( \pm 0.29)$ & $32.02( \pm 1.30)$ & $70.89( \pm 0.84)$ & 57 \\
MAESO/DAPA/WF/NC3 & $70.64( \pm 0.64)$ & $35.54( \pm 0.60)$ & $74.12( \pm 0.08)$ & 60 \\
MAESO/DAPA/WF/NC5 & $68.95( \pm 0.32)$ & $33.47( \pm 0.54)$ & $71.09( \pm 0.71)$ & 58
\end{tabular}

an increase in surface roughness was observed [33]. This was further supported by the FTIR and TEM studies.

\subsection{Mechanical properties}

The flexural, tensile and hardness values of wood polymer composites loaded with various nanoclay percentages is shown in Table 2. The mechanical properties of the composites were dependent on the interactions between wood flour and the polymer matrix. For the composites, both the tensile and flexural strength increased with increasing nanoclay content up to $3 \mathrm{wt} \%$. The improvement in properties at $3 \mathrm{wt} \%$ clay loading could be attributed to the development of strong interactions between the polymer matrix and silicate layers. Also, the presence of bulky hydrogenated phenanthrene ring of DAPA contributed to the improvement of mechanical properties. The decrease in tensile and flexural strength at $5 \mathrm{wt} \%$ of clay loading in the polymer matrix might be due to the formation of agglomerated clay tactoids. FTIR study of composites containing $5 \mathrm{wt} \%$ nanoclay also supported the decrease in interactions between clay and other ingredients in the composites.

From Table 2, it was also observed that the LOI value increased with the increase in the percentage of nanoclay up to $3 \mathrm{wt} \%$, but beyond that, it decreased. Nanoclay particles produced silicate char on the surface of the composites which provided a thermal barrier to the oxygen and heat leading to an improvement in the flame retardant property. At higher MMT loading, the agglomeration of nanoclay resulted in the decrease in interactions and barrier property.

\subsection{Chemical resistance test}

The chemical resistance study for both with and without nanoclay reinforced composites is shown in Fig. 5. The specimens were kept immersed in $4 \%$ acetic acid and $4 \%$ $\mathrm{NaOH}$ solution for the chemical resistance test. From the figure, it was observed that swelling was least in the case of composites treated with $3 \mathrm{wt} \%$ nanoclay. This was due to the formation of a compact structure that arose due to the increase in interfacial adhesion among the resin, crosslinker, wood, and nanoclay. The chemical resistance test
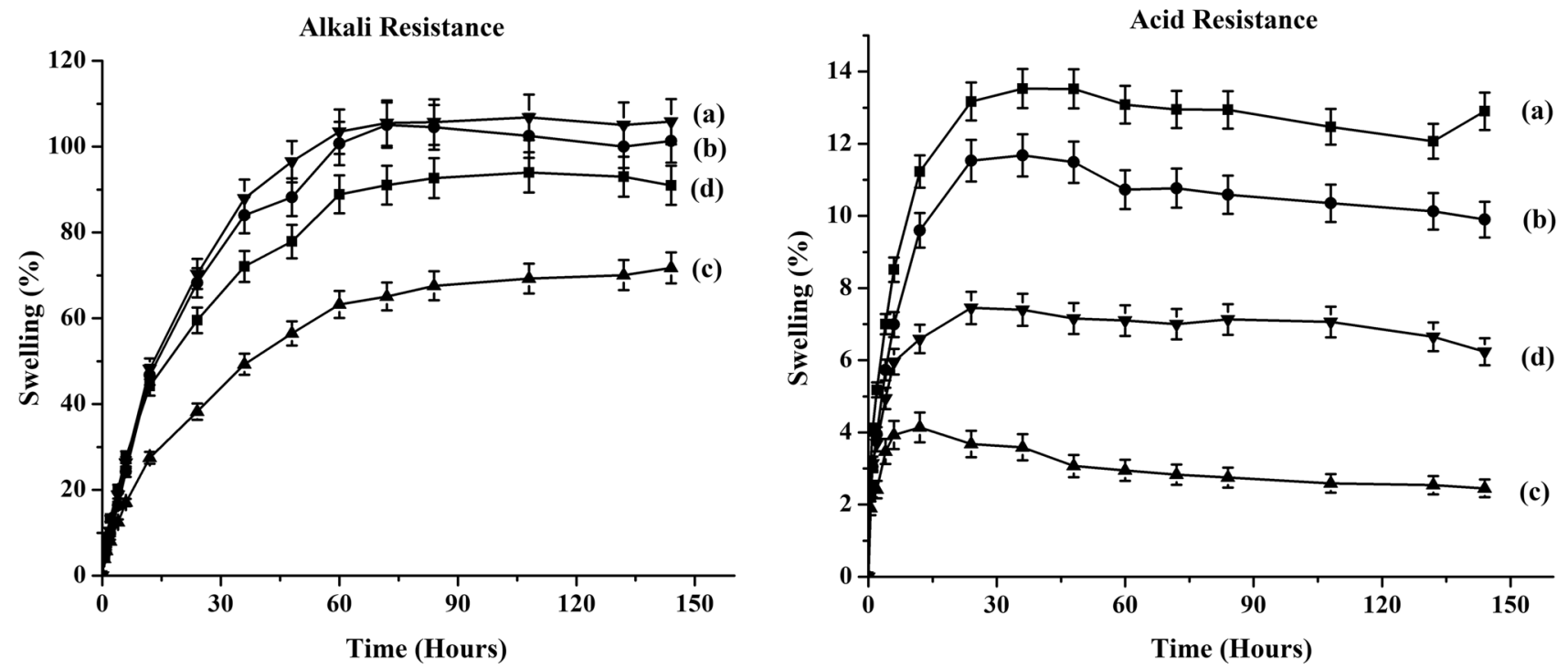

Fig. 5 Chemical resistance of (a) MAESO/DAPA/WF/NCO, (b) MAESO/DAPA/WF/NC1, (c) MAESO/DAPA/WF/NC3 and (d) MAESO/DAPA/WF/ NC5 

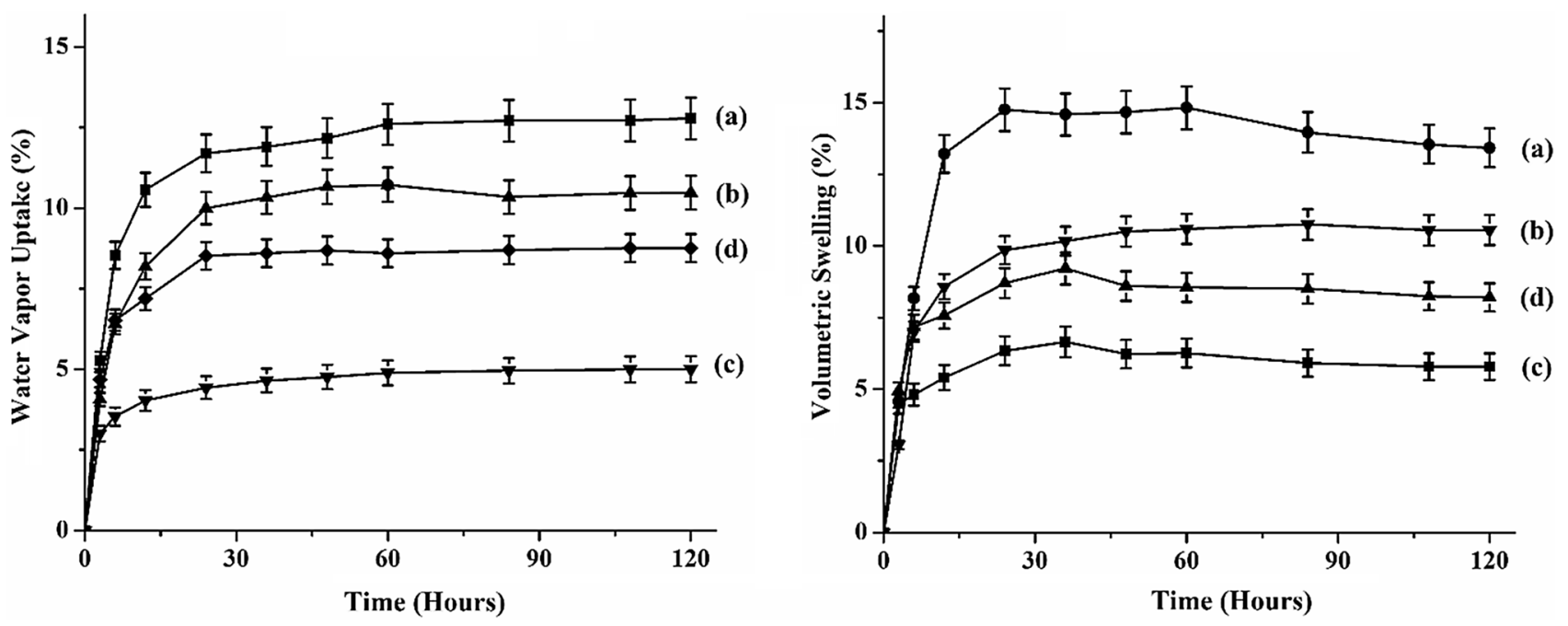

Fig. 6 Water vapor uptake and dimensional stability of (a) MAESO/DAPA/WF/NC0, (b) MAESO/DAPA/WF/NC1, (c) MAESO/DAPA/WF/NC3 and (d) MAESO/DAPA/WF/NC5

indicated that nano-reinforced composite was more resistant towards acid than alkali solution. The lower resistance observed in alkali solution might be due to the increase in interaction by sodium hydroxide with wood cellulose and clay layers [34].

\subsection{Water vapor uptake and dimensional stability test}

The water vapor uptake and dimensional stability of both with and without nanoclay reinforced composites versus time are shown in Fig. 6. The composites loaded with MMT absorbed less moisture than the composite without MMT. The silicate layers of clay provided a barrier to water vapor uptake. The water vapour uptake capacity was least for $3 \mathrm{wt} \%$ of clay loading composite, which might be due to the formation of a compact structure and as a result the accessibility of moisture is restricted. At a higher percentage of clay loading (5 wt\%), agglomeration of clay particles might have occurred. This facilitated the absorption of water vapor resulting in an increase of volumetric swelling.

\subsection{Thermal properties}

The results of thermogravimetric analysis (TGA/DTG) for different composites samples are shown in Fig. 7. The initial decomposition temperature $\left(T_{i}\right)$, maximum pyrolysis temperature $(T m)$, decomposition temperature $\left(T_{D}\right)$ at
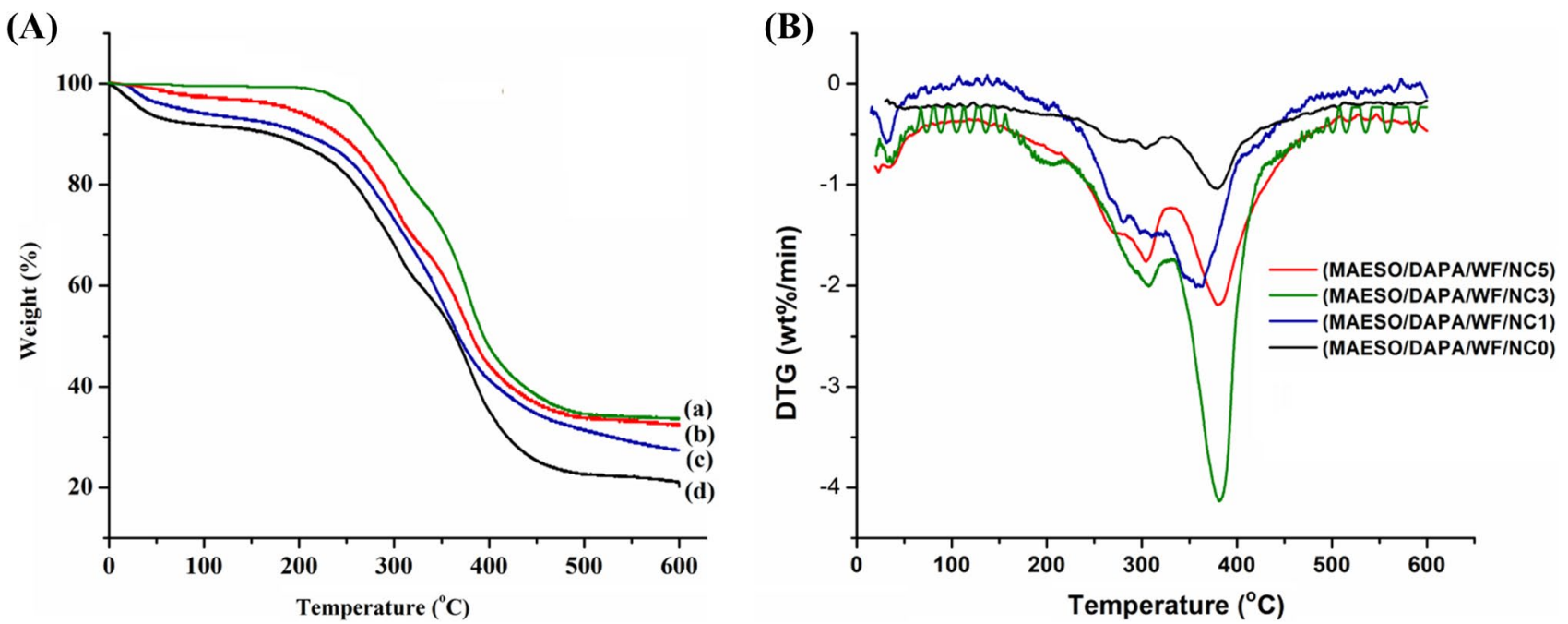

Fig. 7 TGA/DTG curves of (a) MAESO/DAPA/WF/NC3, (b) MAESO/DAPA/WF/NC5, (c) MAESO/DAPA/WF/NC1 and (d) MAESO/DAPA/WF/NC0 
Table 3 Thermal analysis of WPCs both with and without nano-clay

\begin{tabular}{|c|c|c|c|c|c|c|c|}
\hline \multirow[t]{2}{*}{ Sample } & \multirow[t]{2}{*}{$T_{i}$} & \multirow[t]{2}{*}{$T_{m}^{\mathrm{a}}$} & \multirow[t]{2}{*}{$T_{m}^{b}$} & \multicolumn{3}{|c|}{$\begin{array}{l}\text { Temperature of decomposi- } \\
\text { tion }\left(T_{D}\right) \text { in }{ }^{\circ} \mathrm{C} \text { at different } \\
\text { weight loss }(\%)\end{array}$} & \multirow[t]{2}{*}{ RW\% at $600^{\circ} \mathrm{C}$} \\
\hline & & & & $20 \%$ & $40 \%$ & $60 \%$ & \\
\hline MAESO/DAPA/WF/NCO & 210 & 282 & 377 & 280 & 345 & 389 & 22.70 \\
\hline MAESO/DAPA/WF/NC1 & 225 & 287 & 361 & 283 & 347 & 405 & 26.79 \\
\hline MAESO/DAPA/WF/NC3 & 240 & 307 & 382 & 315 & 377 & 427 & 30.82 \\
\hline MAESO/DAPA/WF/NC5 & 230 & 295 & 379 & 290 & 355 & 415 & 30.56 \\
\hline
\end{tabular}

RW, residual weight; $T_{i}$, value for initial degradation; $T_{m}^{\mathrm{a}}$ value for the first step; $T_{m}^{\mathrm{b}}$ value for the second step different weight loss (\%) and residual weight (RW, \%) for composites with and without nanoclay is summarized in Table 3. It can be seen that $T_{i}, T_{m}$, and $T_{D}$ values improve after the incorporation of nanoclay into the polymer composites. All the composites display a loss in weight within the temperature range from 100 to $600^{\circ} \mathrm{C}$. For $20 \%$ weight loss, the decomposition temperature for composite without nanoclay was $280^{\circ} \mathrm{C}$, whereas for $1 \mathrm{wt} \%$ of nanoclay loaded composite, the decomposition temperature was $283^{\circ} \mathrm{C}$. It was observed that the thermal stability of the composite increased to some extent, due to the incorporation of $1 \mathrm{wt} \%$ of nanoclay. The temperature at which $60 \%$ weight loss occurred for the composite without nanoclay was $389^{\circ} \mathrm{C}$, whereas for the composites with different amount of nanoclay $(1,3,5 \mathrm{wt} \%)$ the decomposition temperature was 405,427 and $415^{\circ} \mathrm{C}$, respectively. The appreciable improvement of thermal resistance due to the incorporation of $3 \mathrm{wt} \%$ of nanoclay could be attributed to the development of a confined structure in the composites reinforced with nanoclay. The motion of the polymer chain was restricted by the silica domains, upon the introduction of clay particles into the polymer matrix. This improvement in the thermal stability was also attributed to the existence of the MMT nano-layers, which functions as a barricade to reduce the permeability of volatile degradation products out of the material. Therefore, MAESO/DAPA/WF/ NC3 showed relatively high thermal stability. However, the composite containing $5 \mathrm{wt} \%$ of clay (i.e. MAESO/DAPA/WF/ NC5) showed a reduction in thermal stability. The lower thermal resistance was due to clay aggregates present in the $5 \mathrm{wt} \%$ of clay loaded composites. The residual weight (\%) of nanoclay loaded composites was more than the unloaded one, which might be due to the formation of more char on the surface of the composite when subjected to heat. The char protected the bulk of the composite from temperature and decreased the rate of mass loss throughout the thermal dissipation of the composites. Formation of intensive char in clay loaded composites was an indication for improvement in thermal resistance [35].

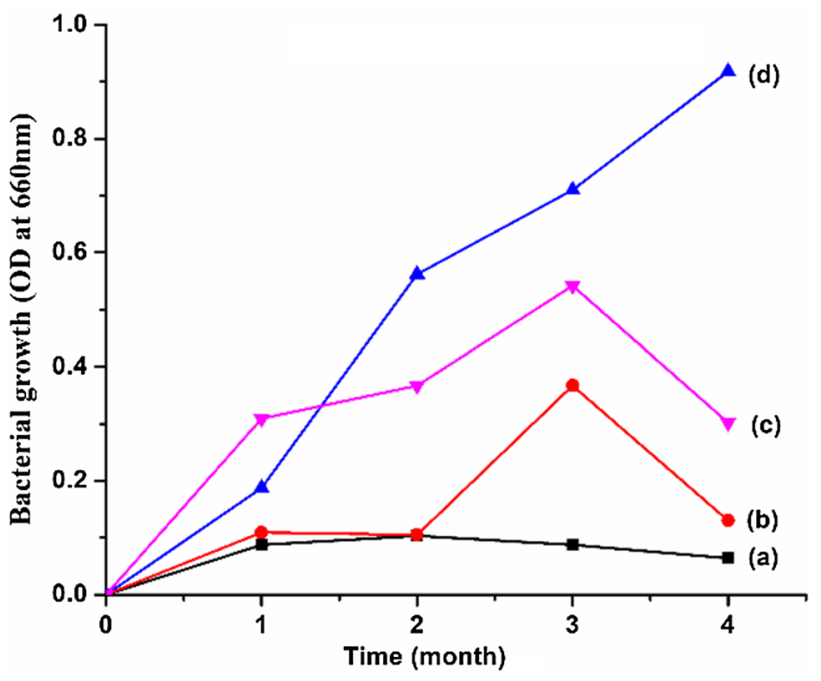

Fig. 8 Bacterial growth on (a) MAESO/DAPA/WF/NC3, (b) MAESO/ DAPA/WF/NC5, (c) MAESO/DAPA/WF/NC1 and (d) MAESO/DAPA/ WF/NCO

\subsection{Biodegradation study}

The composite samples treated with $0,1,3,5 \mathrm{wt} \%$ of MMT were treated with cellulolytic bacterial strain in liquid broth culture medium for the study of biodegradation [36]. The production of bacteria and the rate of biodegradation in the broth culture medium were detectable after 1 month of incubation. During the biodegradation of composites, the bacterial OD increased specifying the usage of the carbon source with the increases in time of incubation. The growth of bacteria (absorbance at $660 \mathrm{~nm}$ ) in the samples is represented in Fig. 8 , with respect to the time. The increase in microbial growth was prominent in the case of the composite without MMT in comparison to the composite filled one. The inclusion of nano-clay declines the collapse of wood composites owing to its antimicrobial activity. Firstly, the development of the bacterial strain rises slowly with the time of exposure. However, after 

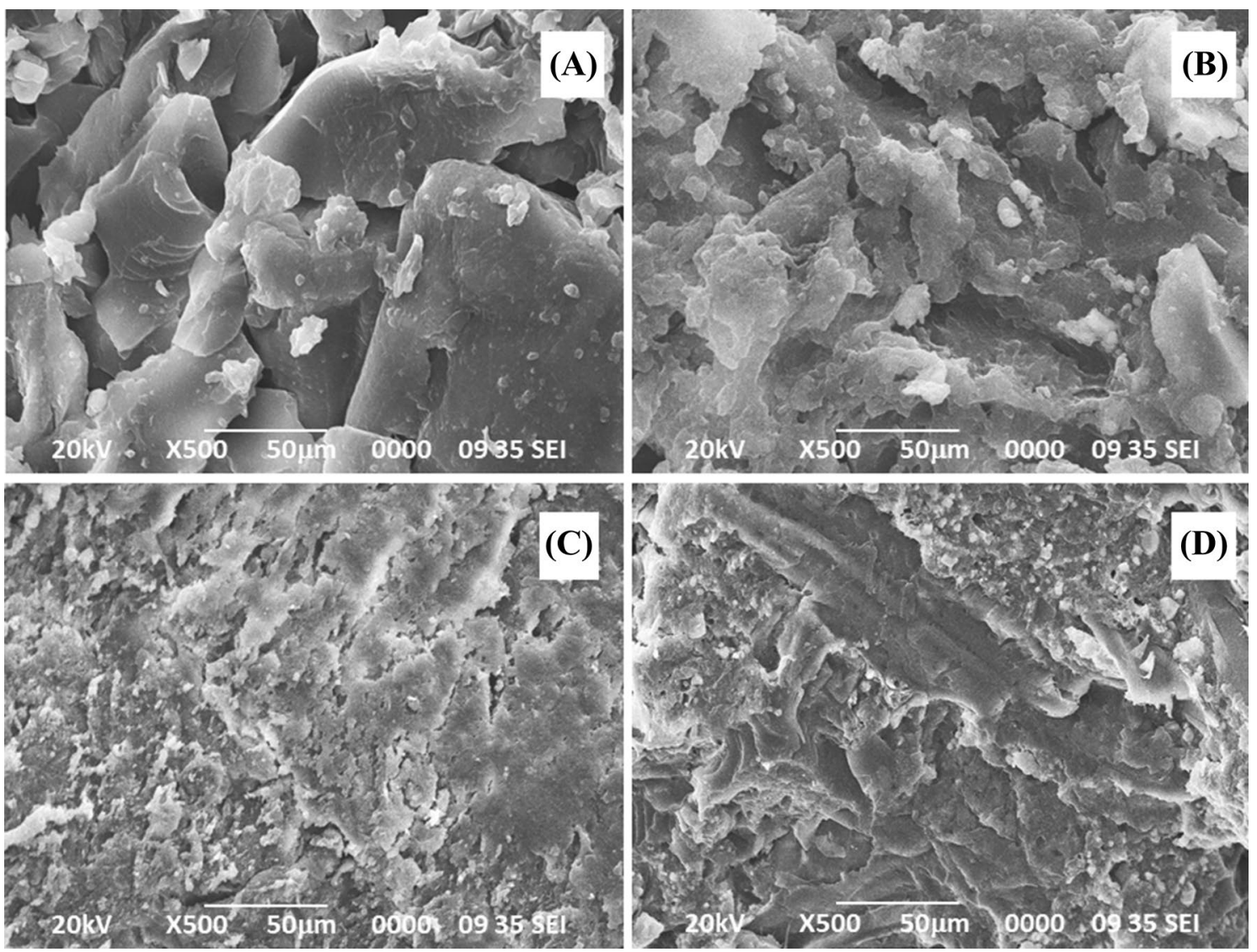

Fig. 9 SEM micrographs of bio-degradable samples a MAESO/DAPA/WF/NC0, b MAESO/DAPA/WF/NC1, c MAESO/DAPA/WF/NC3 and d MAESO/DAPA/WF/NC5

3 months of incubation, it started decreasing in the composites. The bacterial growth was enhanced by the effectual ability of the bacterium Pseudomonas that degraded the lignin present in the wood [37]. Furthermore, the Pseudomonas sp. can produce cellulase and pectinase enzymes that could degrade the cellulose and pectin component present in the wood [38]. The decrease in bacterial growth after 3 months of incubation was because of the generation of inhibitory metabolites through the microbes.

The decomposition of the wood composites due to the bacterial growth was studied by SEM. The SEM images of the biodegraded samples are shown in Fig. 9. The physical breakdown of composites on exposure to microbes suggested that they were inclined to bacterial degradation. The images clearly revealed that the surface was biodegraded and the degradation was prominent in unfilled composites (Fig. 9a) compared to MMT filled composites. The decrease in biodegradation might be due to the strongly interconnected network in the MMT loaded composite which diminished the accessibility and reactivity of microorganisms. Also, the composites treated with nanoclay showed low water absorption capacity thereby inhibiting the penetration of microorganism within the composite. The bio-degradation process of the composite depends on water absorption. Therefore, the composites with greater moisture absorption capacity showed higher biodegradation. The amount of MMT present in the composites highly influenced the biodegradation process. With the increase of MMT up to $3 \mathrm{wt} \%$, the composite showed a decreased rate of biodegradation which was evident
Table 4 Mechanical properties of various WPCs after biodegradation study

\begin{tabular}{lclc}
\hline Sample & Flexural strength $(\mathrm{MPa})$ & Tensile strength $(\mathrm{MPa})$ & Hardness shore D \\
\hline MAESO/DAPA/WF/NC0 & $43.38( \pm 0.29)$ & $19.36( \pm 0.31)$ & $42.14( \pm 0.08)$ \\
MAESO/DAPA/WF/NC1 & $46.31( \pm 0.30)$ & $20.65( \pm 0.22)$ & $42.37( \pm 0.35)$ \\
MAESO/DAPA/WF/NC3 & $50.60( \pm 0.23)$ & $24.67( \pm 0.11)$ & $45.15( \pm 0.08)$ \\
MAESO/DAPA/WF/NC5 & $48.50( \pm 0.43)$ & $22.31( \pm 0.25)$ & $42.55( \pm 0.41)$ \\
\hline
\end{tabular}


Table 5 Decreasing level (\%) of the mechanical property before and after bio-degradation study for various WPCs

\begin{tabular}{llll}
\hline Sample & $\begin{array}{l}\text { Flexural } \\
\text { strength } \\
(\%)\end{array}$ & $\begin{array}{l}\text { Tensile } \\
\text { strength } \\
(\%)\end{array}$ & Hardness (\%) \\
\hline MAESO/DAPA/WF/NC0 & 33.31 & 38.77 & 40.19 \\
MAESO/DAPA/WF/NC1 & 31.01 & 35.50 & 40.23 \\
MAESO/DAPA/WF/NC3 & 28.37 & 30.58 & 39.08 \\
MAESO/DAPA/WF/NC5 & 29.66 & 33.34 & 40.14 \\
\hline
\end{tabular}

Decreasing level $(\%)=($ Mechanical property before biodegradation-Mechanical property after biodegradation/Mechanical property before biodegradation) $* 100$

from the changes in its hardness and mechanical property results (Table 4). The SEM of the $3 \mathrm{wt} \%$ nanoclay containing composite showed less irregularity compared to $1 \mathrm{wt} \%$ of nanoclay based composites, which revealed that the degradation rate was highly affected by the amount of the nano-filler. However, surface unevenness was prominent again in composites reinforced with $5 \mathrm{wt} \%$ of nanoclay, due to the accumulation of the nanoclay particles that increased the biodegradation process [39].

After exposure to the microorganism, there was a decrease in the mechanical properties and hardness values of composites loaded with different percentage of MMT (Table 4). The deterioration of both mechanical and hardness values of composites having $3 \mathrm{wt} \%$ nano clay was least compared to either neat/or other nano composites. This might be due to the higher resistance shown by the composite towards microbial attack. The retention in mechanical properties after the microbial attack was due to better interaction between the wood, DAPA, MMT and MAESO resin that hindered the absorption of moisture eventually decreasing the bacterial attack. However, as they are sensitive to moisture, the $5 \mathrm{wt} \%$ of MMT loading composites showed a decrease in strength retention after the microbial attack. This was due to the agglomeration of MMT particles. The percentage of decrease in mechanical properties (\%) before and after biodegradation for wood polymer composites is shown in Table 5.

\section{Conclusion}

The wood polymer composites cross-linked with rosin derivatives and MMT have been prepared by a compression molding technique. SEM and FTIR results showed that MMT was dispersed uniformly into the polymer matrix. The composites loaded with MMT showed enhanced mechanical, thermal, flame retardance and other properties compared to the neat composites. Also, the MMT loaded composites showed higher resistance to moisture absorption due to the compact structure formed by the interaction among the components of the composites. The mechanical properties of the composite decreased extensively upon exposure to the microorganism. However, the wood composites containing MMT showed higher retention in mechanical properties compared to neat composites due to greater resistance to the microorganism. This renders the wood polymer composites favorable in terms of environmental protection. There was a significant improvement in the thermal, mechanical, and flame retardant properties for the composite with $3 \mathrm{wt} \%$ of nanoclay. MAESO/DAPA/WF/ $\mathrm{NC3}$, displayed minimal water vapour uptake, microbial growth, and maximal chemical resistance. The incorporation of nanoclay improves the overall properties up to the addition of $3 \mathrm{wt} \%$ nanoclay beyond that further addition decreases the properties.

Acknowledgements The authors would like to express their gratitude to the University Grants Commission (UGC), New Delhi, for providing financial assistance (as a fellowship) in carrying out this research. Grant No. 2014-15/RGNF-2014-15-SC-ASS-82974.

\section{Compliance with ethical standards}

Conflict of interest The authors declare that they have no conflict of interest.

\section{References}

1. Mohanty AK, Misra M, Hinrichsen G (2000) Biofibers, biodegradable polymers and biocomposites: an overview. Macromol Mater Eng 1-24:276-277

2. Ashori A, Nourbakhsh A (2010) Bio-based composites from waste agricultural residues. Waste Manage 30:680-684

3. Yu L, Dean K, Li L (2006) Polymer blends \& composites from renewable resources. Prog Polym Sci 31:576-602

4. Pickering KL, Aruan Efendy MG, Le TM (2016) A review of recent developments in natural fibre composites and their mechanical performance. Compos A 83:98-112

5. Devi RR, Maji TK (2013) In situ polymerized wood polymer composite: effect of additives and nanoclay on the thermal and mechanical properties. Mater Res 16:954-963

6. Kord B (2011) Effect of nanoparticles loading on properties of polymeric composite based on Hemp fiber/polypropylene. J Thermoplast Compos Mater 25:793-806

7. Zhao Y, Wang K, Zhu F, Xue P, Jia M (2006) Properties of poly(vinylchloride)/wood-flour/montmorillonite composites: effects of coupling agents and layered silicate. Polym Degrad Stab 91:2874-2883

8. Hetzer M, Kee D (2008) Wood/polymer/nanoclay composites, environmentally friendly sustainable technology: a review. Chem Eng Res Des 16:1016-1027

9. Hemmasi A, Khademieslam H, Talaiepoor M, Ghasemi I, Kord B (2010) Effect of nano-clay on the mechanical and morphological properties of wood polymer nanocomposite. J Reinf Plast Compos 29:964-971 
10. Ray S, Okamoto M (2003) Polymer/layered silicate nanocomposites: a review from preparation to processing. Prog Polym Sci 28:1539-1641

11. Dong X, Zhuo X, Wei J, Zhang G, Li Y (2017) Wood-based nanocomposite derived by in situ formation of organic-inorganic hybrid polymer within wood via a sol-gel method. ACS Appl Mater Interfaces 9:9070-9078

12. Miao S, Wang P, Su Z, Zhang S (2014) Vegetable-oil-based polymers as future polymeric biomaterials. Acta Biomater 10:1692-1704

13. Mohanty AK, Misra M, Drzal LT (2002) Sustainable bio-composites from renewable resources: opportunities and challenges in the green materials world. J Polym Environ 10:19-26

14. Miao S, Sun L, Wang P, Liu R, Su Z, Zhang S (2012) Soybean oil based polyurethane networks as candidate biomaterials: synthesis and biocompatibility. Eur J Lipid Sci Technol 114:1165-1174

15. Meier MA, Metzger JO, Schubert US (2007) Plant oil renewable resources as green alternatives in polymer science. Chem Soc Rev 36:1788-1802

16. Montero de Espinosa L, Meier MA (2011) Plant oils: the perfect renewable resource for polymer science. Eur Polym J 47:837-852

17. Adekunle K, Akesson D, Skrifvars M (2010) Synthesis of reactive soybean oils for use as a biobased thermoset resins in structural natural fiber composites. Appl Polym Sci 115:3137-3145

18. Adekunle KF (2014) Bio-based polymers for technical applications: a review-part 2. OJPC 4:95-101

19. Khot SN, Lascala JJ, Can E, Morye SS, Williams GI, Palmese GR, Kusefoglu SH, Wool RP (2001) Development and application of triglyceride-based polymers and composites. J Appl Polym Sci 82:703-723

20. Liu XQ, Xin WB, Zhang JW (2009) Rosin-based acid anhydrides as alternatives to petrochemical curing agents. Green Chem 11:1018-1025

21. Wang HH, Liu XQ, Zhang JW, Xian M (2009) Synthesis of rosinbased flexible anhydride type curing agents and properties of the cured epoxy. Polym Int 58:1435-1441

22. Ma Q, Liu X, Zhang R, Zhu J, Jiang Y (2013) Synthesis and properties of full bio-based thermosetting resins from rosin acid and soybean oil: the role of rosin acid derivatives. Green Chem $15: 1300-1310$

23. Njuguna J, Pielichowski K, Desai S (2008) Nanofiller-reinforced polymer nanocomposites. Polym Adv Technol 19:947-959

24. Hussain F, Hojjati M, Okamoto M, Gorga RE (2006) Review article: Polymer-matrix nanocomposites, processing, manufacturing, and application: an overview. J Compos Mater 40:1511-1575

25. Zanetti M, Lomakin S, Camino G (2000) Polymer layered silicate nanocomposites. Macromol Mater Eng 279:1-9
26. Goettler LA, Lee KY, Thakkar H (2007) Layered silicate reinforced polymer nanocomposites: development and applications. Polym Rev 47:291-317

27. LeBaron PC, Wang Z, Pinnavaia TJ (1999) Polymer-layered silicate nanocomposites: an overview. Appl Clay Sci 15:11-29

28. Mandal M, Borgohain P, Begum P, Deka RC, Maji TK (2018) Property enhancement and DFT study of wood polymer composites using rosin derivatives as co-monomers. NJC 42:2260-2269

29. Mandal M, Maji TK (2017) Comparative study on the properties of wood polymer composites based on different modified soybean oils. J Wood Chem Technol 37:124-135

30. Hazarika A, Maji TK (2017) Ultraviolet resistance and other physical properties of softwood polymer nanocomposites reinforced with ZnO nanoparticles and nanoclay. Wood Mater Sci Technol 12:24-39

31. Mandal M, Maji TK (2018) Preparation, physical properties and ultraviolet resistance of wood nanocomposites based on modified soybean oil and bentonite. Wood Mater Sci Eng 14:381-391

32. Mustapha SNH, Rahmat AR, Arsad A (2014) Bio-based thermoset nanocomposite derived from vegetable oil: a short review. Rev Chem Eng 30:167-182

33. Liu H, Cui S, Shang S, Wang D, Song J (2013) Properties of rosinbased waterborne polyurethanes/cellulose nanocrystals composites. Carbohydr Polym 96(2):510-515

34. Hazarika A, Maji TK (2013) Study on the properties of wood polymer nanocomposites based on melamine formaldehydefurfuryl alcohol copolymer and modified clay. J Wood Chem Technol 33:103-124

35. Deng L, Shen M, Yu J, Wu K, Ha C (2012) Preparation, characterization, and flame retardancy of novel rosin-based siloxane epoxy resins. Ind Eng Chem Res 51:8178-8184

36. Deka BK, Mandal M, Maji TK (2012) Effect of nanoparticles on flammability, UV resistance, biodegradability, and chemical resistance of wood polymer nanocomposite. Ind Eng Chem Res $51: 11881-11891$

37. Yang JS, Ni JR, Yuan HL, Wang E (2007) Biodegradation of three different wood chips by Pseudomonas sp. PKE117. Int Biodeterior Biodegrad 60:90-95

38. Clausen CA (1996) Bacterial associations with decaying wood: a review. Int Biodeterior Biodegrad 37:101-107

39. Abrahama E, Elbi PA, Deepa B, Jyotishkumar P, Pothen LA, Narine SS, Thomas S (2012) X-ray diffraction and biodegradation analysis of green composites of natural rubber/nanocellulose. Polym Degrad Stab 97:2378-2387

Publisher's Note Springer Nature remains neutral with regard to jurisdictional claims in published maps and institutional affiliations. 